\title{
Optimization of the characterization of porous carbons for supercapacitors
}

\author{
Fritz Stoeckli* ${ }^{a}$ and Teresa A. Centeno $*^{b}$ \\ ${ }^{a}$ Department of Physics,University of Neuchâtel,Emile Argand 9, 2000 Neuchâtel, Switzerland. \\ ${ }^{b}$ Instuto Nacional del Carbón-CSIC, Apartado 73, 33080 Oviedo, Spain.
}

The optimization of carbon-based supercapacitors is of great technological importance for electrical energy storage. This challenge stresses the relevance of current attempts to increase the surface-related capacitance $\mathrm{C} / \mathrm{S}\left(\mathrm{F} \mathrm{m}^{-2}\right)$ of carbons. We show that for microporous carbons this property is practically constant for pore widths between 0.7 and $1.8 \mathrm{~nm}$. The study is based on two independent approaches, (i) the effective surface area accessible to the ions, which may differ considerably from the BET-surface and (ii) the volumetric capacitance in the micropores. One obtains $0.094 \mathrm{~F} \mathrm{~m}^{-2}$ for $\left(\mathrm{C}_{2} \mathrm{H}_{5}\right)_{4} \mathrm{NBF}_{4}$ /acetonitrile and approximately $0.100 \mathrm{~F} \mathrm{~m}^{-2}$ in aqueous $\mathrm{H}_{2} \mathrm{SO}_{4}$ after correcting for pseudo-capacitance effects. This pattern is supported by recent modelling which takes into account the solvent. It is also suggested that constant values of the surface based-capacitance may reflect a gradual decrease of the dielectric constant of the electrolytes in smaller micropores due to desolvation.

\section{Introduction}

In view of the large surface area associated with their narrow pores, microporous carbons are used widely in supercapacitors. On the other hand, meso- and macroporous carbons also present specific advantages, such as favourable transport properties for electrolyte ions, in spite of their decreasing surface area to volume ratio.

The improvement of supercapacitors based on porous carbons requires a careful characterization of these materials and the identification of the parameters responsible for their electrochemical properties. In this context, the effective surface relatedcapacitance $\left(\mathrm{F} \mathrm{m}^{-2}\right)$ and the volumetric capacitance $\left(\mathrm{F}\right.$ per $\mathrm{cm}^{3}$ of micropores) are key factors for the development of high-performance carbons.

Whereas the determination of the gravimetric capacitance $\mathrm{C}\left(\mathrm{F} \mathrm{g}^{-1}\right)$ relies on wellestablished techniques, its conversion into a surface-related quantity $\mathrm{C} / \mathrm{S}\left(\mathrm{F} \mathrm{m}^{-2}\right)$ presents problems, due to the determination of the surface area accessible to the organic and aqueous electrolytes. A popular approach used in this context rests on the BET method, but it has been pointed out in a IUPAC recommendation ${ }^{1}$ and in various studies, ${ }^{2-8}$ that this technique may lead to incorrect values of the specific surface area of microporous solids. On the other hand, a number of independent techniques suggest coherent values which can differ considerably from $\mathrm{S}_{\mathrm{BET}}$, depending on the pore width. 
This, in turn, implies differences in $\mathrm{C} / \mathrm{S}$ of microporous carbons, which may lead to different conclusions. Therefore, we feel that this situation should be pointed out, in particular as it is relevant to theoreticians who rely on experimental data in order to verify their models describing electrolytes such as $\left(\mathrm{C}_{2} \mathrm{H}_{5}\right)_{4} \mathrm{NBF}_{4} /$ acetonitrile and aqueous $\mathrm{H}_{2} \mathrm{SO}_{4}$. On the other hand, reliable information is required to guide the technological development of supercapacitors with optimal performance.

Here we summarize some recent developments ${ }^{4,9-12}$ in the characterization of microporous carbons based on either the surface area determined by a combination of different techniques, or the volumetric capacitance in the micropores. It is shown that these converging approaches lead to important consequences for the search of suitable carbons for supercapacitors. It is also suggested that the constant value of $\mathrm{C} / \mathrm{S}$ may reflect a change in the dielectric constant $\varepsilon_{\mathrm{r}}$ of the electrolyte in the pores.

\section{Experimental}

\subsection{Textural characterization of carbons}

The study is based on porous carbons of different origins. They are found in ref. (9-10), with their main textural, calorimetric and electrochemical properties. The textural characterization was performed by gas adsorption and immersion calorimetry. The use of carbon tetrachloride $(0.63 \mathrm{~nm})$ and norbornadiene $(0.65 \mathrm{~nm})$ in both the vapour and liquid states ${ }^{9}$ allowed the determination of the surface area accessible to the relatively large $\left(\mathrm{C}_{2} \mathrm{H}_{5}\right)_{4} \mathrm{~N}^{+}$ion $(0.68 \mathrm{~nm}) .{ }^{13}$ For each carbon the average total surface area $\mathrm{S}_{\mathrm{av}}$ was determined with the help of the combination of different techniques. In the case of samples taken from a recent and detailed study, ${ }^{9}$ up to six different determinations were used.

\subsection{Electrochemical measurements}

The electrochemical performances were tested in a sandwich-type capacitor set up with two carbon pellets ( $8 \mathrm{~mm}$ diameter, around $350 \mu \mathrm{m}$ thick) separated by glassy fibrous paper (300 $\mu \mathrm{m}$ thick) and placed in a Swagelock cell. The electrodes were obtained by pressing a mixture of the carbon $(75 \% \mathrm{wt})$, PVDF $(20 \% \mathrm{wt})$ as binder and carbon black (Super P, $5 \% \mathrm{wt}$ ). The electrolytes were $2 \mathrm{M} \mathrm{H}_{2} \mathrm{SO}_{4}$ aqueous solution and $1 \mathrm{M}$ $\left(\mathrm{C}_{2} \mathrm{H}_{5}\right)_{4} \mathrm{NBF}_{4}$ in acetonitrile $\left(\mathrm{TEABF}_{4} / \mathrm{AN}\right)$. The capacitance was determined by galvanostatic charge-discharge cycles (Autolab-Ecochimie PGSTAT 30) at a constant current density of $1 \mathrm{mAcm}^{-2}$. The cell voltage ranged from 0 to $0.8 \mathrm{~V}$ for aqueous medium and between 0 and $2 \mathrm{~V}$ for the organic electrolyte. The gravimetric capacitance 
$\left(\mathrm{F} \mathrm{g}^{-1}\right)$ given in the present study is relative to the carbon mass in a single electrode. The accuracy with our laboratory-scale device was around $\pm 5 \%$.

\section{Results and discussion}

\subsection{Determination of the specific surface area of carbon materials}

The porosity of carbons can be divided into three domains, depending on the pore sizes, ${ }^{1}$ namely microporosity $(<2 \mathrm{~nm}$, mesoporosity $(2-50 \mathrm{~nm})$ and macroporosity $(>50$ $\mathrm{nm}$ ). In recent years, micropores and small mesopores have also been called nanopores. To a first and probably good approximation, micropores can be considered as locally slit-shaped, at least in the range of widths up to $1.2-1.3 \mathrm{~nm}$ and similar lateral dimensions.

This approximation, inherent to the basic structure of carbons, is now commonly used in the modelling of their adsorption and electrochemical properties. This structure has already been suggested by high resolution electron microscopy ${ }^{14}$ and by the dark-field technique of Oberlin et al. ${ }^{15-17}$

As discussed recently, ${ }^{4}$ the total surface area in porous carbons can be assessed by at least four independent techniques such as Dubinin's theory, ${ }^{9,18-20}$ Kaneko's comparison plot, $^{21}$ the selective adsorption of phenol from aqueous solutions ${ }^{22,23}$ and the density functional theory (DFT) in its more recent expression NLDFT, ${ }^{24}$ as well as Monte Carlo modelling. ${ }^{25-27}$ Kaneko's comparison plot and the adsorption of phenol are modelindependent, as they rest on the comparison with an open surface (graphitized carbon black). The average total surface $S_{a v}$ obtained from the different determinations appears to be more reliable than that estimated by the BET equation, $\mathrm{S}_{\mathrm{BET}}$. These techniques are outlined below.

In the case of microporous carbons, the main textural properties can be obtained from the adsorption of gases and vapours (e.g. nitrogen at $77 \mathrm{~K}$ or benzene near room temperature) analyzed in the framework of Dubinin's theory for the volume filling of micropores. ${ }^{4,18-20}$ This theory can also be extended to immersion calorimetry into the corresponding liquids, ${ }^{17,19,20}$ which provides either a means to cross-check the adsorption data, or provide complementary information. One of them is the determination of the pore size distribution (PSD) based on the use of liquids of different molecular dimensions. ${ }^{13,24,25-27}$ 
The basic expression is the Dubinin-Astakov equation which relates the thermodynamic potential $\mathrm{A}=\mathrm{RT} \ln \left(\mathrm{p}_{\mathrm{s}} / \mathrm{p}\right)$ to the volume $\mathrm{W}$ of condensed vapour filling the total micropore volume $\mathrm{W}_{\mathrm{o}}$,

$\mathrm{W}=\mathrm{W}_{\mathrm{o}} \exp \left[-\left(\mathrm{A} / \beta \mathrm{E}_{\mathrm{o}}\right)^{\mathrm{n}}\right]$

Exponent $\mathrm{n}$ varies between 1.5 and 3, depending on the width of the pore size distribution, and for most carbons $\mathrm{n}=2$, which corresponds to the classical DubininRadushkevich (DR) equation. $\beta$ is a parameter depending on the adsorbate.

It has been shown ${ }^{19,20,28}$ that the characteristic energy $E_{o}$ is related to the average width $\mathrm{L}_{\mathrm{o}}$ of slit-shaped micropores by the equation:

$\mathrm{L}_{\mathrm{o}}(\mathrm{DR})(\mathrm{nm})=10.8 /\left[\mathrm{E}_{\mathrm{o}}\left(\mathrm{kJmol}^{-1}\right)-11.4\right]$

For typical PSDs with a single maximum, the surface area of slit-shaped micropores is close to the simple geometrical relation:

$\mathrm{S}_{\mathrm{mi}}\left(\mathrm{m}^{2} \mathrm{~g}^{-1}\right)=2000 \mathrm{~W}_{\mathrm{o}}\left(\mathrm{cm}^{3} \mathrm{~g}^{-1}\right) / \mathrm{L}_{\mathrm{o}}(\mathrm{nm})$

It follows, that for microporous carbons the total surface area is:

$\mathrm{S}_{\mathrm{tot}}(\mathrm{DR})=\mathrm{S}_{\mathrm{mi}}+\mathrm{S}_{\mathrm{e}}$

where $S_{e}$ (external surface) is the area found in larger pores and on the outside of the sample. The external surface can be obtained by different techniques, such as comparison plots, ${ }^{21,29,30}$ the analysis of the hysteresis loop on desorption, ${ }^{29}$ and by immersion calorimetry. ${ }^{9,19}$ These values are usually in good agreement.

Another approach to estimate the total surface area of carbons is the Kaneko's comparison plot method, ${ }^{21}$ which is a development of Sing's $\alpha$-plot. ${ }^{29}$ It is valid for pores above $0.6 \mathrm{~nm}$ and one compares the amounts of $\mathrm{N}_{2}$ adsorbed by the given sample and by a non-porous reference. ${ }^{30}$ The slopes of the initial and the final sections of the plot multiplied by the specific surface of the reference sample $\left(\mathrm{m}^{2} \mathrm{~g}^{-1}\right)$ correspond, respectively, to the total surface area $S_{\text {comp }}$ and to the external surface area $S_{e}$ of the 
solid. In principle this technique can also be applied to other adsorbates such as benzene, dichloromethane and carbon tetrachloride.

Since phenol adsorbed by carbons from dilute aqueous solutions forms a monolayer on the surface of carbons, this property can be used to determine the surface of the micropore walls with the help of the liquid-solid isotherm. On the other hand, the total surface area can be determined by immersion calorimetry., ${ }^{4,22,23}$ Based on a reference value of $-0.105 \pm 0.004 \mathrm{~J} \mathrm{~m}^{-2}$, the enthalpy of immersion into $0.4 \mathrm{M}$ aqueous solution of phenol leads to the total surface area $S_{\text {phe }}$ of carbons.

The current non linear density functional theory (NLDFT) plays a major role in the characterization of microporous carbons and the approach based $\mathrm{N}_{2}$ at $77 \mathrm{~K}$ features in a recent ISO standard. ${ }^{31}$ It considers homogeneous slit-shaped pores, but unlike the Monte Carlo approach, its pore size distribution suffers from a false gap in the region of $1 \mathrm{~nm}$. This feature may introduce some uncertainty in the surface area $\mathrm{S}_{\mathrm{NLDFT}}$ and the micropore volume. This shortcoming has been corrected in the recent QSLDFT model. ${ }^{32}$

As illustrated by a few examples (Table 1), the different techniques lead to total surface $\operatorname{areas}^{4,9}$ which are in good agreement, as indicated by the standard deviation of their average value $\mathrm{S}_{\mathrm{av}}=\left[\mathrm{S}_{\mathrm{tot}}(\mathrm{DR})+\mathrm{S}_{\mathrm{comp}}+\mathrm{S}_{\mathrm{phe}}+\mathrm{S}_{\mathrm{NLDFT}}\right] / 4$. The table also gives $\mathrm{S}_{\mathrm{tot}}\left(\mathrm{CCl}_{4}\right)$, the total surface area accessible to $\mathrm{CCl}_{4}$ on the corresponding carbons. This area is discussed in more detail below and it is relevant in the case of the organic electrolyte $\left(\mathrm{C}_{2} \mathrm{H}_{5}\right)_{4} \mathrm{NBF}_{4}$ in acetonitrile $\left(\mathrm{TEABF}_{4} / \mathrm{AN}\right){ }^{9,10}$

As implied by the data of Table 1, the determination of surface-related properties may lead to strongly diverging results, depending on the choice of the surface area. Moreover, depending on the pore size distribution and the size of the adsorbed molecule or ion, even $\mathrm{S}_{\mathrm{av}}$ or $\mathrm{S}_{\mathrm{NLDFT}}$ cannot be used in a straightforward manner. 
Table 1. Specific surface areas for typical microporous carbons ${ }^{9}$

\begin{tabular}{lllll}
\hline Carbon & $\begin{array}{l}\mathrm{L}_{\mathrm{o}} \\
(\mathrm{nm})\end{array}$ & $\begin{array}{l}\mathrm{S}_{\mathrm{av}} \\
\left(\mathrm{m}^{2} \mathrm{~g}^{-1}\right)\end{array}$ & $\begin{array}{l}\mathrm{S}_{\mathrm{tot}}\left(\mathrm{CCl}_{4}\right) \\
\left(\mathrm{m}^{2} \mathrm{~g}^{-1}\right)\end{array}$ & $\begin{array}{l}\mathrm{S}_{\mathrm{BET}} \\
\left(\mathrm{m}^{2} \mathrm{~g}^{-1}\right)\end{array}$ \\
\hline HK-650-8 & 0.66 & $1000 \pm 170$ & $374 \pm 15$ & 661 \\
PAU-1 & 0.73 & $1266 \pm 60$ & $930 \pm 36$ & 1001 \\
CMS-H2 & 0.81 & $686 \pm 33$ & $500 \pm 20$ & 567 \\
DCG-5 & 1.15 & $956 \pm 85$ & $827 \pm 15$ & 1121 \\
M1R & 1.23 & $1072 \pm 20$ & $1072 \pm 20$ & 1555 \\
KF-1500 & 1.38 & $987 \pm 66$ & $977 \pm 66$ & 1568 \\
N-125-08 & 1.60 & $791 \pm 40$ & $846 \pm 40$ & 1317 \\
\hline
\end{tabular}

The specific surface area estimated by the BET equation, $\mathrm{S}_{\mathrm{BET}}$, often diverges from the other determinations, but in some cases one observes an agreement between $\mathrm{S}_{\mathrm{BET}}$ and $\mathrm{S}_{\mathrm{av}}$. A systematic study of a large variety of carbons with average pore widths $\mathrm{L}_{\mathrm{o}}$ between 0.66 and $1.65 \mathrm{~nm}$ suggests that ${ }^{4}$

$\mathrm{S}_{\mathrm{BET}} / \mathrm{S}_{\mathrm{av}}=(1.19 \pm 0.03) \mathrm{L}_{\mathrm{o}}$

Eqn. (5) shows that both areas are equal for pore widths around 0.8-1.0 nm (Fig. 1section II), which explains the satisfactory results observed for certain carbons. On the other hand, below 0.8-0.9 $\mathrm{nm} \mathrm{S}_{\mathrm{BET}}$ underrates the more realistic surface area $\mathrm{S}_{\mathrm{av}}$ (Fig. 1section I) and it gradually overrates it between 1 and 3-4 nm (Fig. 1- section III). Finally, they become similar in wide pores. 


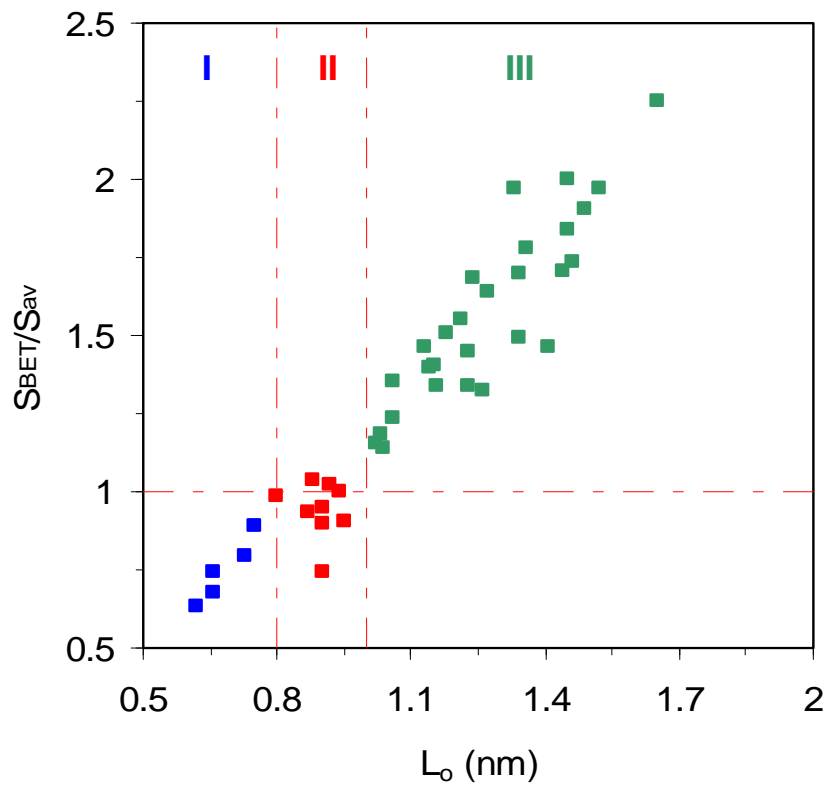

Fig. 1. Variation of $\mathrm{S}_{\mathrm{BET}} / \mathrm{S}_{\mathrm{av}}$ with the average micropore size $\mathrm{L}_{\mathrm{o}}$.

Figure 2 shows that in the case of nitrogen adsorbed at $77 \mathrm{~K}$, there is a clear correlation between $\left(\mathrm{S}_{\mathrm{BET}}-\mathrm{S}_{\mathrm{e}}\right)$, the part of the BET

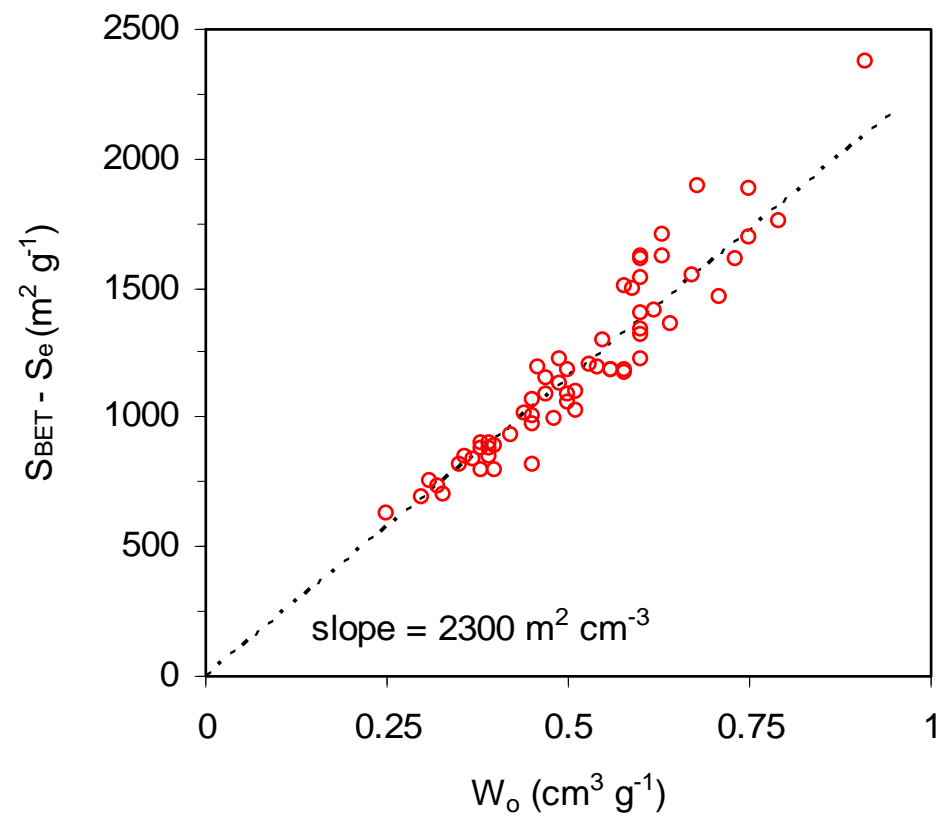

Fig. 2. Correlation between the surface area $\mathrm{S}_{\mathrm{BET}}-\mathrm{S}_{\mathrm{e}}$ and the micropore volume $\mathrm{W}_{\mathrm{o}}$ for a variety of microporous carbons $4,9,10,13$

As illustrated by Figure 3, this means that, with the exception of pores around 0.8-0.9 $\mathrm{nm}$ (domain II) which can accommodate two layers of nitrogen molecules, $\left(\mathrm{S}_{\mathrm{BET}}-\mathrm{S}_{\mathrm{e}}\right)$ 
reflects the area equivalent to the total volume adsorbed in the micropores, rather than the surface area of the micropores walls, $\mathrm{S}_{\mathrm{mi}}$.

I
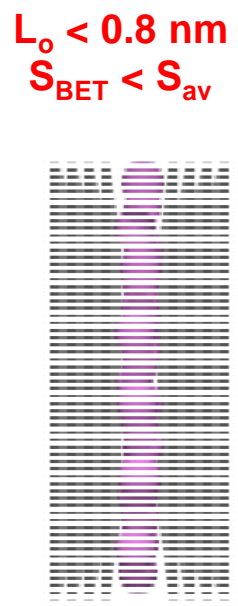

II

$\mathrm{L}_{\mathrm{o}} \sim 0.8-0.9 \mathrm{~nm}$

$\mathrm{S}_{\mathrm{BET}}=\mathrm{S}_{\mathrm{av}}$

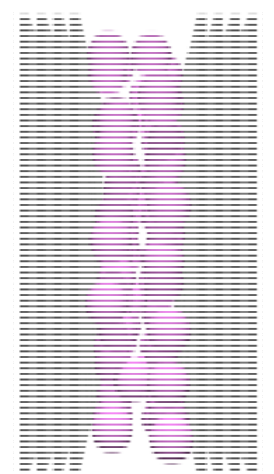

III

$\mathrm{L}_{\mathrm{o}}>1 \mathrm{~nm}$

$\mathrm{S}_{\mathrm{BET}}>\mathrm{S}_{\mathrm{av}}$

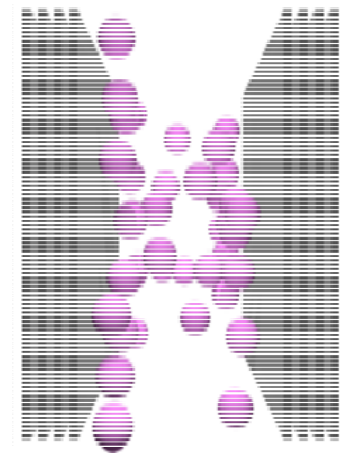

Fig. 3. Adsorption of nitrogen at $77 \mathrm{~K}$ in slit-shaped micropores of different widths. Around $0.8-0.9 \mathrm{~nm}$ there are two layers.

These results show that $\mathrm{S}_{\mathrm{av}}$ is more reliable than $\mathrm{S}_{\mathrm{BET}}$, with the corresponding consequences on surface-related properties of carbons such as the capacitance $\mathrm{C} / \mathrm{S}$. However, it must be emphasized that $\mathrm{S}_{\mathrm{av}}$ corresponds to the area accessible to small molecules or ionic species. If one uses larger probes, such as $\mathrm{CCl}_{4}(0.63 \mathrm{~nm})$ or the $\left(\mathrm{C}_{2} \mathrm{H}_{5}\right)_{4} \mathrm{~N}^{+}$ion $(0.68 \mathrm{~nm}),{ }^{33}$ the accessible surface area may be limited by the pore size distribution and/or the presence of constrictions at the entrance of pores which could accommodate these probes. In the case of the cation of the organic electrolyte $\left(\mathrm{C}_{2} \mathrm{H}_{5}\right)_{4} \mathrm{~N}^{+}$, the determination of the accessible surface area requires a specific study based on the adsorption of $\mathrm{CCl}_{4}$ from both the vapour and the liquid phase. As shown elsewhere, ${ }^{9,34}$ the analysis of the $\mathrm{CCl}_{4}$ adsorption isotherm with the help of Dubinin's theory and the determination of the enthalpy of immersion into this liquid provide converging results. They lead to the typical values given in Table 1 and it appears that for carbons with average pore sizes below $1 \mathrm{~nm}$ the total surface area $\mathrm{S}_{\text {tot }}\left(\mathrm{CCl}_{4}\right)$ can often be smaller than $\mathrm{S}_{\mathrm{av}}$. 


\subsection{Specific capacitance $\mathrm{C} / \mathrm{S}$ of microporous carbons in the organic electrolyte $\mathrm{TEABF}_{4} / \mathrm{AN}$}

As illustrated by Figure 4, the study of various carbons ${ }^{9,10}$ with pore sizes between 0.7 and $1.8 \mathrm{~nm}$ clearly shows the difference in the surface-related capacitance based on the one hand on $\mathrm{S}_{\mathrm{BET}}$ and, on the other hand, on $\mathrm{S}_{\mathrm{av}}$ or $\mathrm{S}_{\mathrm{tot}}\left(\mathrm{CCl}_{4}\right)$.

The dotted line shows the trend for $\mathrm{C} / \mathrm{S}_{\mathrm{BET}}(\square)$ and it includes data for carbide-based carbons $(\boldsymbol{\Delta})$, where capacitances as high as $0.14 \mathrm{~F} \mathrm{~m}^{-2}$ have been reported. ${ }^{33,35}$ The latter data led to the hypothesis of an anomalous increase at pore widths below 1 to 1.1 $\mathrm{nm}$. On the other hand, it appears that the values estimated by using the more reliable total surface areas $\mathrm{C} / \mathrm{S}_{\mathrm{av}}$ or $\mathrm{C} / \mathrm{S}_{\text {tot }}\left(\mathrm{CCl}_{4}\right)(\square)$, remain relatively constant between 0.7 and $1.8 \mathrm{~nm}$. A local increase in the surface related-capacitance is not excluded for certain carbons, but such a trend is no longer significant in the overall pattern of Figure 4, because equally high capacitances are observed in pores well above $1 \mathrm{~nm}$.

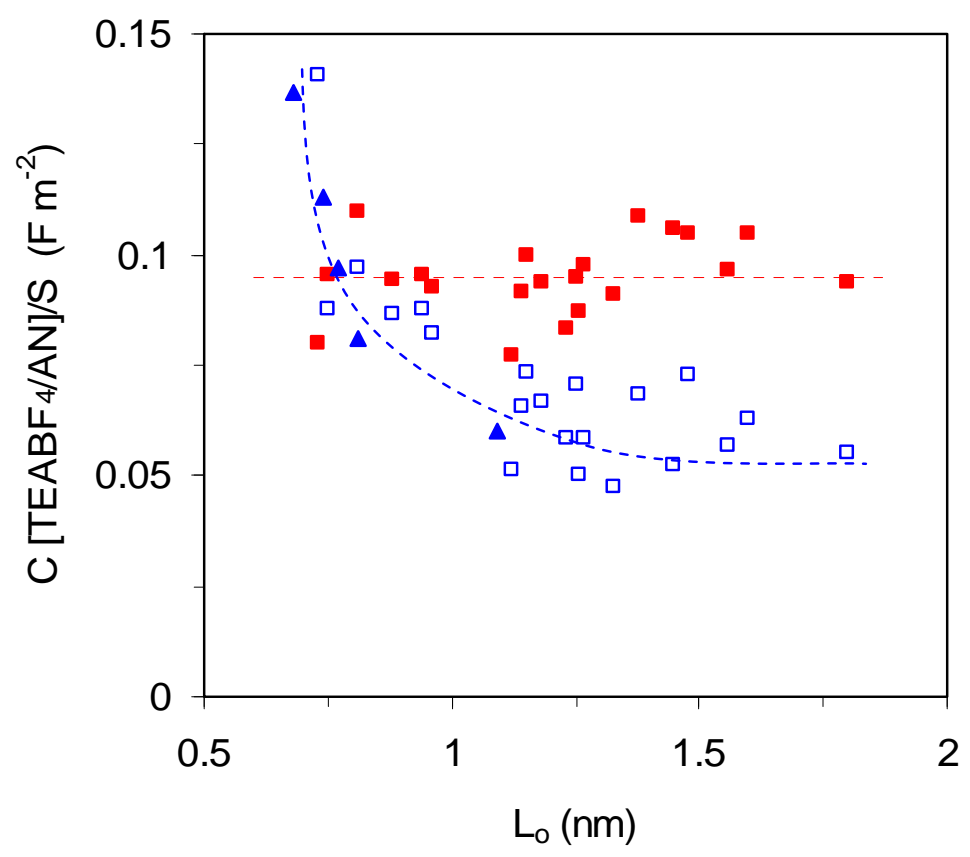

Fig. 4. Variation of the surface capacitances $\mathrm{C} / \mathrm{S}_{\mathrm{BET}}(\square)$ and $\mathrm{C} / \mathrm{S}_{\mathrm{av}}$ or $\mathrm{C} / \mathrm{S}_{\text {tot }}\left(\mathrm{CCl}_{4}\right)(\square)$ in the organic electrolyte $\left(\mathrm{TEABF}_{4} / \mathrm{AN}\right)$ for various carbons with their average micropore width $\mathrm{L}_{\mathrm{o}}$. Specific capacitances for five carbide-based carbons, ${ }^{33,35}$ referred to $\mathrm{S}_{\mathrm{BET}}(\boldsymbol{\Delta})$, are also included. 
Our detailed analysis ${ }^{9}$ based on 22 carbons characterized by up to 6 different determinations of $\mathrm{S}_{\mathrm{av}}$ shows that between 0.7 and $1.8 \mathrm{~nm}$ the average value of $\mathrm{C}\left(\mathrm{TEABF}_{4} / \mathrm{AN}\right) / \mathrm{S}_{\mathrm{av}}$ is $0.094 \pm 0.011 \mathrm{~F} \mathrm{~m}^{-2}$. This value may be compared with earlier estimates of approximately 0.08 to $0.09 \mathrm{~F} \mathrm{~m}^{-2}$ for this electrolyte. ${ }^{7,36-38}$ It also agrees with additional data for 6 mesoporous carbons with diameters $D_{p}$ between 3.4 and 15.7 nm. ${ }^{9}$

This pattern is also confirmed by the study of Feng et $a .^{8}$ on activated carbon beads, using $\mathrm{TEABF}_{4} /$ polypropylene carbonate as electrolyte. This work shows the discrepancy between $\mathrm{S}_{\mathrm{NLDFT}}$ and $\mathrm{S}_{\mathrm{BET}}$. The analysis of $\mathrm{C} / \mathrm{S}$ based on $\mathrm{S}_{\mathrm{NLDFT}}$ considered simultaneously the surface areas of the different types of pores (micro- and mesopores) present in these solids, which leads to $0.087,0.099$ and $0.097 \mathrm{~F} \mathrm{~m}^{-2}$ at pore widths below $1 \mathrm{~nm}$, between 1 and $2 \mathrm{~nm}$, and above $2 \mathrm{~nm}$, respectively. Although the solvent (polypropylene carbonate) is different, these values are similar to those shown in Figure 4 and it appears again that $\mathrm{C} / \mathrm{S}$ is independent of the average micropore width. A possible explanation for this behaviour is discussed below.

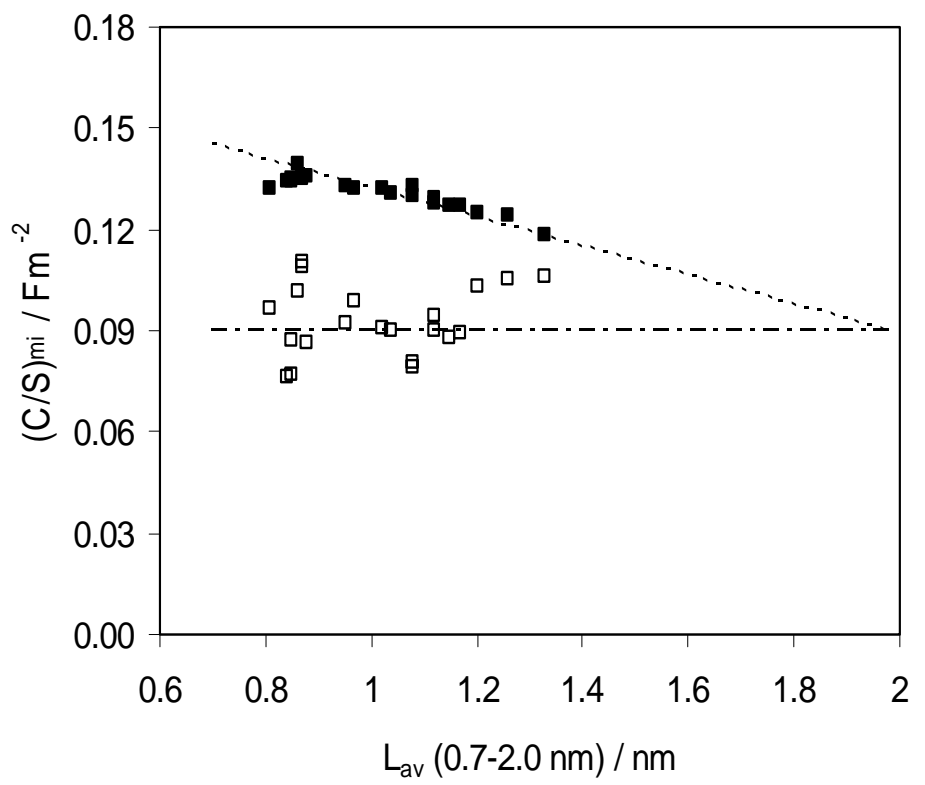

Fig. 5. Experimental values of the specific capacitance in the micropores $(C / S)_{\mathrm{mi}}(\square)$ and the values recalculated from the NLDFT-based PSDs( $(\mathbf{})$, assuming a linear increase in $\mathrm{dC} / \mathrm{dS}$ from 0.094 to $0.140 \mathrm{~F} \mathrm{~m}^{-2}$ between 2.0 and $0.75 \mathrm{~nm}$. (Reproduced from [12] by permission of the PCCP Owner Societies) 
The possibility that the pore size distributions (PSDs) may hide an increase of the underlying capacitance $\mathrm{dC} / \mathrm{dS}$, suggested by some authors ${ }^{39-42}$ has also been examined by using different functions $\mathrm{dC} / \mathrm{dS}=\mathrm{f}(\mathrm{L}) .^{12}$ As illustrated by Figure 5 , calculations showed that the PSDs of our microporous carbons, determined by NLDFT, only hide relatively small variations of $(\mathrm{C} / \mathrm{S})_{\mathrm{mi}}$, the surface-related capacitance in the micropores The experimental capacitance $\mathrm{C} / \mathrm{S}$ of typical microporous carbons reported by us, including carbide-derived carbons with narrow PSDs, ${ }^{36}$ remains therefore around $0.09 \pm$ $0.01 \mathrm{Fm}^{-2}$ for pore widths between 0.7 and $2 \mathrm{~nm}$. By extension, the same conclusions should apply to aqueous electrolytes, following a correction for pseudo-capacitance effects.

\subsection{Volumetric capacitance of microporous carbons in the organic electrolyte} TEABF4/AN

Although the capacitance is essentially a surface-based effect, it is interesting to examine the volumetric capacitance in the micropores, $\mathrm{C}_{\mathrm{mi}} / \mathrm{W}_{\mathrm{o}}\left(\mathrm{F} \mathrm{cm}^{-3}\right)$ and to correlate it with the foregoing result for $\mathrm{C} / \mathrm{S}_{\mathrm{av}}\left(\mathrm{F} \mathrm{m}^{-2}\right)$. This has been reported recently, ${ }^{11}$ by considering $\mathrm{W}_{\mathrm{o}}\left(\mathrm{CCl}_{4}\right)$, the volume accessible to the probe $\mathrm{CCl}_{4}$, and the corresponding average pore width $\mathrm{L}_{0}\left(\mathrm{CCl}_{4}\right)$ of the PSD probed by this molecule. This value is suggested by the analysis of the $\mathrm{CCl}_{4}$ isotherm, using Eqn. (2). In the case of the $\mathrm{TEABF}_{4} / \mathrm{AN}$ electrolyte, this information is more accurate than the data based on small probes such as nitrogen or benzene. $\mathrm{W}_{\mathrm{o}}\left(\mathrm{CCl}_{4}\right)$ and $\mathrm{S}_{\text {tot }}\left(\mathrm{CCl}_{4}\right)$ correspond closely to the volume and the surface area accessible to the $\left(\mathrm{C}_{2} \mathrm{H}_{5}\right)_{4} \mathrm{~N}^{+}$ion $(0.68 \mathrm{~nm})$. For carbons with average pore widths below $1 \mathrm{~nm}$, or with constrictions, the accessibility may indeed be reduced, as revealed by the ratio between the enthalpies of immersion into $\mathrm{CCl}_{4}$ and into $\mathrm{C}_{6} \mathrm{H}_{6}$. This is the case for a few carbons of the present selection, where the ratios of the enthalpies are below 0.97 , the value predicted by the extension of Dubinin's theory to immersion calorimetry. ${ }^{9,19,20}$ 


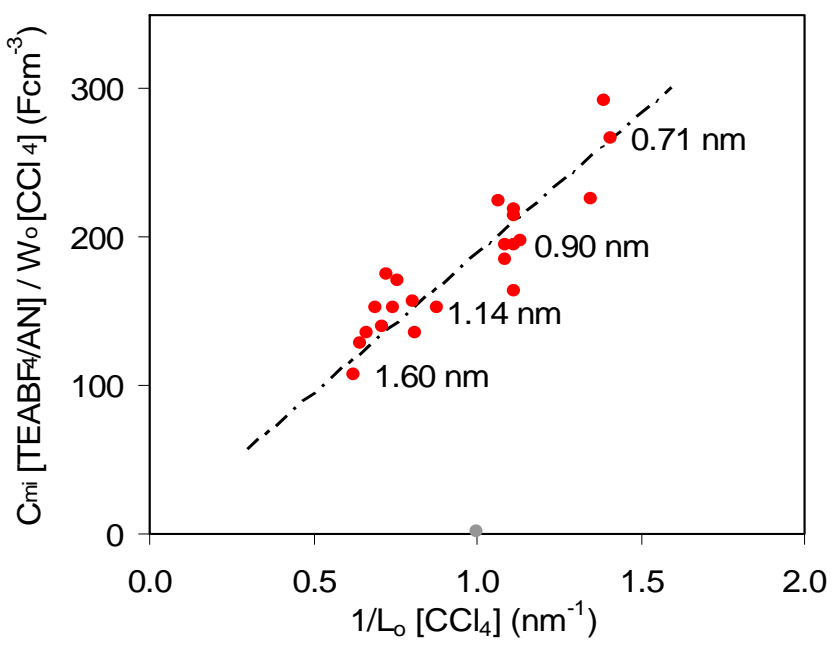

Fig. 6. Variation of the volumetric capacitance in micropores $\mathrm{C}_{\mathrm{mi}}\left[\mathrm{TEABF}_{4}\right] / \mathrm{W}_{\mathrm{o}}\left[\mathrm{CCl}_{4}\right]$ with $1 / \mathrm{L}_{\mathrm{o}}\left[\mathrm{CCl}_{4}\right]$ for the carbons of ref. [9].

Following a relatively small correction of $0.094 \mathrm{~S}_{\mathrm{e}}\left(\mathrm{F} \mathrm{g}^{-1}\right)$ corresponding to the capacitance of the external surface area $S_{e}$, one obtains the gravimetric capacitance $C_{m i}$ associated with the micropores. (For the present samples, this correction is small). As shown in Figure $6, \mathrm{C}_{\mathrm{mi}}(\mathrm{TEABF} / \mathrm{AN}) / \mathrm{W}_{\mathrm{o}}\left(\mathrm{CCl}_{4}\right)$ is a linear function of $1 / \mathrm{L}_{\mathrm{o}}\left(\mathrm{CCl}_{4}\right)$ with a slope of $188 \pm 5 \mathrm{~F} \mathrm{~cm}^{-3} \mathrm{~nm}$. In view of Eqn. (3), $\mathrm{C}_{\mathrm{mi}} / \mathrm{W}_{\mathrm{o}}=\left(2000 \mathrm{C}_{\mathrm{mi}} / \mathrm{S}_{\mathrm{mi}}\right)\left(1 / \mathrm{L}_{\mathrm{o}}\right)$ and, therefore, the slope corresponds to a surface-related capacitance of approximately $188 / 2000=0.094 \mathrm{~F} \mathrm{~m}^{-2}$ for slit-shaped micropores, which is not too surprising. The higher values of $\mathrm{C}_{\mathrm{mi}}\left(\mathrm{TEABF}_{4} / \mathrm{AN}\right) \mathrm{W}_{\mathrm{o}}\left(\mathrm{CCl}_{4}\right)$ in smaller micropores reflect the higher surface/volume ratio, as expected, but the linearity of the graph implies that the surfacerelated capacitance is relatively constant in the range of 0.7 to $1.6 \mathrm{~nm}$. By analogy with the recent study illustrated by Figure 5 , an underlying variation $\mathrm{dC} / \mathrm{dS}$ of the specific capacitance would also lead to a change in the regular pattern of Figure 6.

The present approach has the advantage that it avoids the problem related to the surface areas $\mathrm{S}_{\mathrm{av}}$ and $\mathrm{S}_{\mathrm{BET}}$, because $\mathrm{W}_{\mathrm{o}}\left(\mathrm{CCl}_{4}\right)$ and $\mathrm{L}_{\mathrm{o}}\left(\mathrm{CCl}_{4}\right)$ are reliable quantities, which can be determined unambiguously.

The study of the volumetric capacitance provides therefore an independent confirmation of a relatively constant surface-related capacitance in slit-shaped micropores.

At industrial scale, where the volume of the device is a key factor, the much higher volumetric capacitance in smaller pores is interesting. However, it presents adverse effects since the ions transport during the supercapacitor charge-discharge is more restricted in pores with sizes similar to those of the ions. The increasing internal pore 
resistance in narrow micropores also leads to a decrease in the capacitance at high current densities and in the power capability.

\subsection{Specific capacitance $\mathrm{C} / \mathrm{S}$ of microporous carbons in the aqueous electrolyte} $\mathrm{H}_{2} \mathrm{SO}_{4}$

In the case of electrolytes such as aqueous solutions of $\mathrm{H}_{2} \mathrm{SO}_{4}$ and $\mathrm{KOH}$, the experimental capacitance also includes contributions from so-called pseudocapacitive effects due to the redox processes involving surface functionalities.

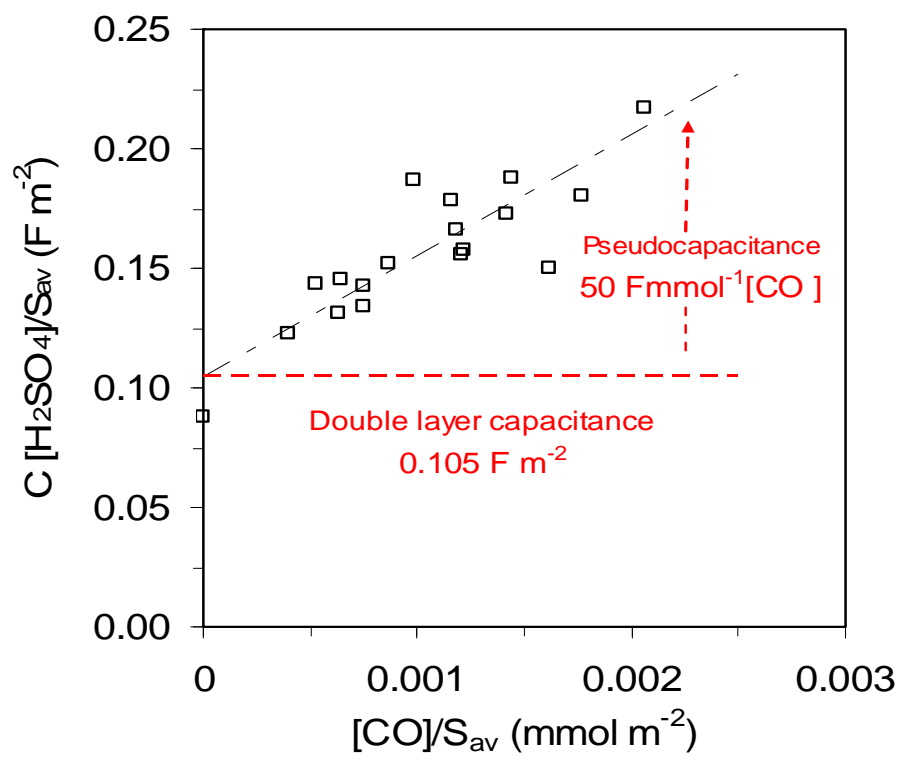

Fig. 7. Variation of the specific capacitance $\mathrm{C}\left[\mathrm{H}_{2} \mathrm{SO}_{4}\right] / \mathrm{S}_{\mathrm{av}}$ with $[\mathrm{CO}] / \mathrm{S}_{\mathrm{av}}$. The horizontal line corresponds to the double layer capacitance suggested by Eqn. (6).

Different authors ${ }^{37,43-45}$ have reported an empirical correlation between $\mathrm{C}\left(\mathrm{H}_{2} \mathrm{SO}_{4}\right) / \mathrm{S}_{\mathrm{BET}}$ and the amount of $\mathrm{CO}$ evolved in thermally programmed desorption [CO]. In the case of 18 carbons, ${ }^{10}$ the plot of $\mathrm{C}\left(\mathrm{H}_{2} \mathrm{SO}_{4}\right) / \mathrm{S}_{\mathrm{av}}$ versus $[\mathrm{CO}] / \mathrm{S}_{\mathrm{av}}$ illustrated by Figure 7 leads to the correlation

$$
\mathrm{C}\left(\mathrm{H}_{2} \mathrm{SO}_{4}\right) / \mathrm{S}_{\mathrm{av}}\left(\mathrm{F} \mathrm{m}^{-2}\right)=(0.105 \pm 0.007)+(50 \pm 6)[\mathrm{CO}] / \mathrm{S}_{\mathrm{av}}
$$

The pseudocapacitance contribution of approximately $50 \mathrm{~F}$ per $\mathrm{mmol}$ of $\mathrm{CO}$ is somewhat smaller than the value of $75 \mathrm{~F}$ per mmol CO reported by Bleda-Martinez et 
al. ${ }^{43}$ who used $\mathrm{C}\left(1 \mathrm{M} \mathrm{H}_{2} \mathrm{SO}_{4}\right) / \mathrm{S}_{\mathrm{BET}}$. However, for our samples the use of $\mathrm{S}_{\mathrm{BET}}$ leads to a larger scatter and $65 \pm 12 \mathrm{~F}$ per mmol $\mathrm{CO}$. These values correspond to typical and untreated activated carbons, whereas smaller values are observed for activated fibres. ${ }^{45}$ This probably reflects differences in the nature of surface complexes involved in the pseudocapacitance effects. A similar pattern applies to the $6 \mathrm{M} \mathrm{KOH}$ electrolyte. ${ }^{9}$

By using the value of $50 \mathrm{~F}$ per mmol of $\mathrm{CO}$ evolved in TPD, the experimental capacitances can be corrected and one obtains the effective double layer capacitances shown in Figure 8. In spite of a slightly larger dispersion, the pattern obtained for the corrected capacitances ( $\boldsymbol{\Xi}$ ) is similar to that shown in Figure 4. This suggests an identical behaviour for both types of electrolytes in micropores, characterized by the absence of a trend in $\mathrm{C} / \mathrm{S}$.

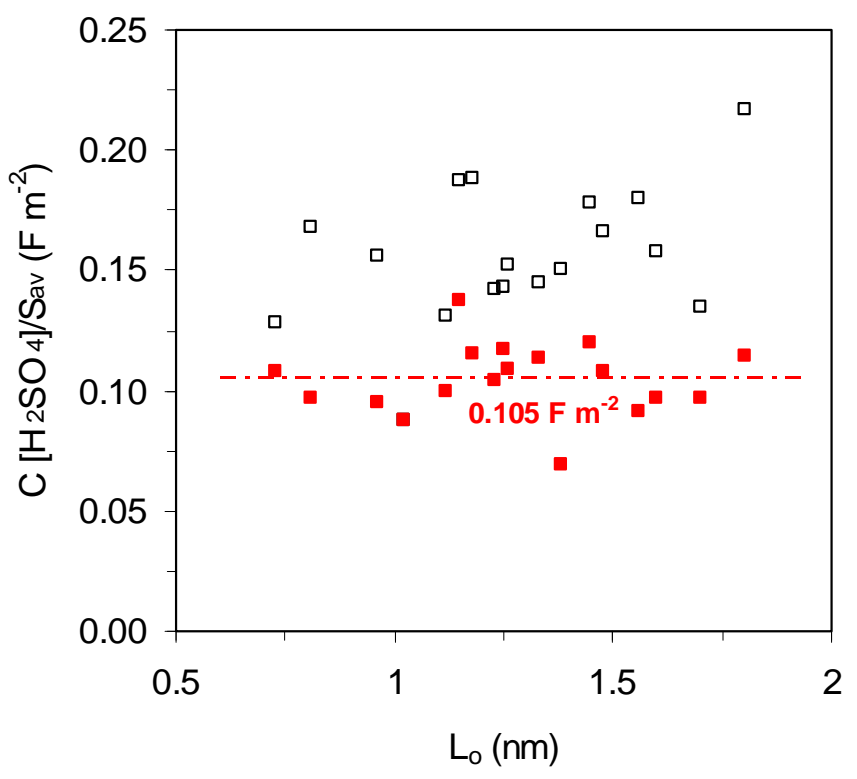

Fig. 8. Uncorrected ( $\square$ ) and corrected ( $\square$ ) capacitances $\mathrm{C}_{(}\left(\mathrm{H}_{2} \mathrm{SO}_{4}\right) / \mathrm{S}_{\mathrm{av}}$ of microporous carbons vs. the average micropore size $\mathrm{L}_{\mathrm{o}}$. Reproduced from [10] by permission of Elsevier.

By analogy with the organic electrolyte, the corrected gravimetric capacitances of the acidic electrolyte also lead to a linear plot of the volumetric capacitance $\mathrm{C}_{\mathrm{mi}}\left(\mathrm{H}_{2} \mathrm{SO}_{4}\right) / \mathrm{W}_{\mathrm{o}}$ versus $1 / L_{0}$, where $W_{o}$ and $L_{o}$ correspond to small probes. The slope of approximately $200 \mathrm{~F} \mathrm{~cm}^{-3} \mathrm{~nm}$ corresponds to $0.100 \mathrm{~F} \mathrm{~m}^{-2}$ and would again suggest a relatively constant value of $\mathrm{C} / \mathrm{S}$ at pore-widths between 0.7 and $1.8 \mathrm{~nm}$. However, the uncertainty is somewhat larger than in the case of the organic electrolyte. 
This is due to the uncertainties in the correction for pseudocapacitance effects, which depend on the nature of the chemical groups. ${ }^{43,45}$

\subsection{Comparison with models and possible interpretations of constant C/S capacitances}

The use of $\mathrm{S}_{\mathrm{av}}$ or $\mathrm{S}_{\mathrm{tot}}\left(\mathrm{CCl}_{4}\right)$, with the appropriate correction for the pseudocapacitance effects in the case of the aqueous electrolyte, suggests that $\mathrm{C} / \mathrm{S}$ does not depend on the width of micropores between 0.7 and $1.8 \mathrm{~nm}$, and probably beyond. This fundamental difference with the increase of $\mathrm{C} / \mathrm{S}_{\mathrm{BET}}$ at pore widths below $1.2 \mathrm{~nm}$ has consequences on the development of carbons used in supercapacitors. It suggests that, at low current density, the total surface area is more important than the corresponding pore width, but small pores present an advantage due to the higher surface to volume ratio and the higher volumetric capacitance.

It is also interesting to examine the experimental data for $\mathrm{C} / \mathrm{S}$ in relation to models suggested to describe the surface-related capacitance in the micropores of activated carbons. For example, following Huang et al., ${ }^{46,47}$ in cylindrical mesopores of radius b the ions can form a double layer of thickness $d$ on the walls and

$\mathrm{C} / \mathrm{S}\left(\mathrm{F} \mathrm{m}^{-2}\right)=\varepsilon_{\mathrm{r}} \varepsilon_{\mathrm{o}} / \mathrm{b} \ln [(\mathrm{b} /(\mathrm{b}-\mathrm{d})]$

On the other hand, in cylindrical micropores the reduced diameter no longer allows the formation of a double layer and it is assumed that the ion of radius $a_{0}$ occupies a central position along the axis of the cylinder (Electric wire model). This leads to

$\mathrm{C} / \mathrm{S}\left(\mathrm{F} \mathrm{m}^{-2}\right)=\varepsilon_{\mathrm{r}} \varepsilon_{0} / \mathrm{b} \ln \left(\mathrm{b} / \mathrm{a}_{\mathrm{o}}\right)$

However, cylindrical micropores are unlikely in microporous carbons, as suggested by high resolution electron microscopy ${ }^{9-12}$ and by the analysis of the PSDs calculated for this type of pores. 

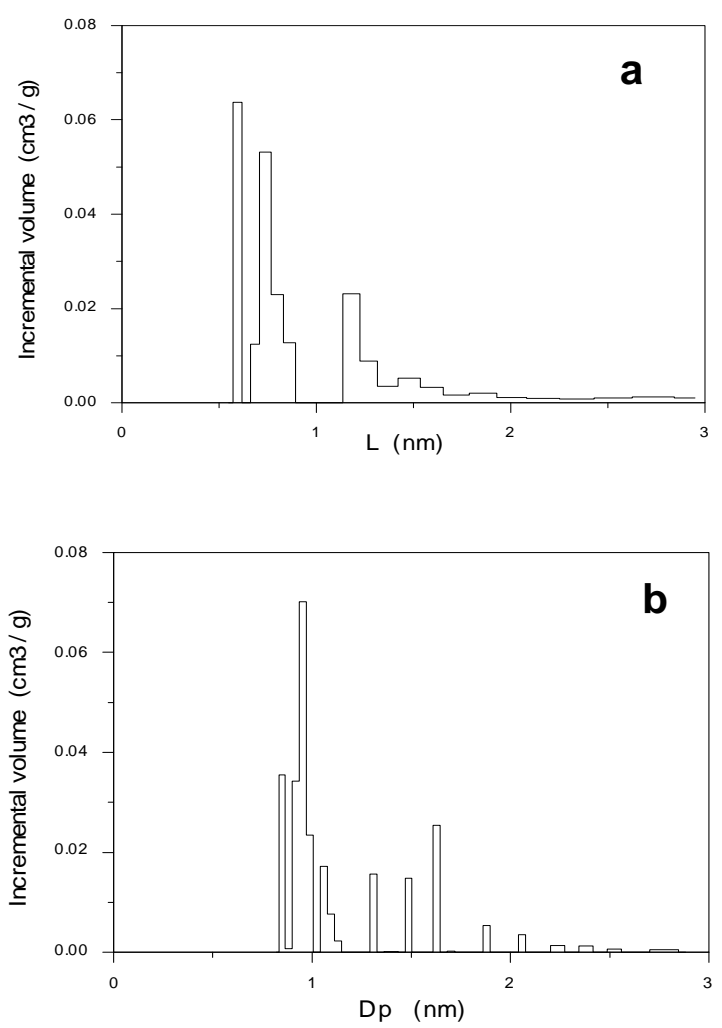

Fig. 9. PSDs of carbon CMS-H2 from NLDFT $\left(\mathrm{N}_{2} ; 77 \mathrm{~K}\right)$ modelling for slits (a) and cylinders (b)

For example, Figure 9 shows the pore size distributions of carbon CMS-H2 for both slitshaped (a) and cylindrical (b) micropores. They are calculated from the same experimental nitrogen isotherm with the help of a standard NLDFT program (Micromeritics ASAP 2010) which provides both models.

The pattern revealed by Figure 8 is typical and the study of the 18 carbons of ref. (6) shows that

(i) The PSD of the cylindrical pores is systematically shifted towards higher values of the pore diameter $\mathrm{D}_{\mathrm{p}}$ with respect to the widths $\mathrm{L}$ of the corresponding slits. Since the minimum size is mostly near $0.8 \mathrm{~nm}$, this profile suppresses the selectivity in the range of 0.4 to $0.7 \mathrm{~nm}$ observed directly in experiments based on the adsorption of molecules with different size (e.g. $\mathrm{CH}_{2} \mathrm{Cl}_{2}, \mathrm{C}_{6} \mathrm{H}_{6}$, cyclo- $\mathrm{C}_{6} \mathrm{H}_{12}, \mathrm{CCl}_{4}$ ) and on the enthalpies of immersion into the corresponding liquids. ${ }^{9,13,19}$ The PSDs based on slit-shaped micropores (NLDFT and Monte Carlo techniques) are in good agreement with these effects, which provides another confirmation of the modelling. 
(ii) The cumulative surface areas of the cylindrical micropores $\mathrm{S}_{\text {NLDFT-CYL }}$ are systematically higher than $\mathrm{S}_{\mathrm{av}}$ or $\mathrm{S}_{\text {NLDFT-SLIT }}$ obtained for the model of slit-shaped pores. It also appears that the specific capacitances $\mathrm{C}\left(\mathrm{TEABF}_{4} / \mathrm{AN}\right) / \mathrm{S}_{\mathrm{NLDFT}-\mathrm{CYL}}$ are remarkably constant for all carbons $\left(0.051 \pm 0.02 \mathrm{~F} \mathrm{~m}^{-2}\right)$, in spite of the considerable differences in their average pore widths $(0.8$ to $2 \mathrm{~nm})$. However, this feature is not realistic, since $\mathrm{S}_{\mathrm{NLDFT}-C Y L}$ is quite different from $\mathrm{S}_{\mathrm{av}}$ and $\mathrm{C} / \mathrm{S}$ is also smaller than the experimental value of 0.08 to $0.09 \mathrm{~F} \mathrm{~m}^{-2}$ reported for wider pores.

These shortcomings suggest that the model of cylindrical micropores and the use of the underlying Eqn. (8) do not apply to microporous carbons. On the other hand, the 'sandwich' model recently proposed by Feng et al. ${ }^{48}$ is more realistic and it can provide important clues as far as constant values of $\mathrm{C} / \mathrm{S}$ are concerned. Based on molecular modelling, it assumes that the solvated ion (in the specific example $\mathrm{K}^{+}$and $\mathrm{H}_{2} \mathrm{O}$ ) occupies a central position in narrow slit-shaped micropores of 0.9 to $1.5 \mathrm{~nm}$ between graphene sheets. The corresponding expression for the surface-related capacitance is

$$
\mathrm{C} / \mathrm{S}\left(\mathrm{F} \mathrm{m} \mathrm{m}^{-2}\right)=\varepsilon_{\mathrm{r}} \varepsilon_{\mathrm{o}} /\left(\mathrm{b}-\mathrm{a}_{\mathrm{o}}\right)
$$

where $b$ represents the half width of the pore, $L / 2$.

It is likely that this model can be used for other electrolytes such as $\mathrm{H}_{2} \mathrm{SO}_{4} / \mathrm{H}_{2} \mathrm{O}$ and $\mathrm{TEABF}_{4} / \mathrm{AN}$. For the latter, the pores must obviously be wider than $0.68 \mathrm{~nm}$, the size of the $\left(\mathrm{C}_{2} \mathrm{H}_{5}\right)_{4} \mathrm{~N}^{+}$ion.

Assuming implicitly that the dielectric constant $\varepsilon_{\mathrm{r}}$ is constant, Feng et al. arrive at the conclusion that the model implies an increase of $\mathrm{C} / \mathrm{S}$ as the pore width $\mathrm{L}=2 \mathrm{~b}$ decreases. This appears to be the case of $6 \mathrm{M} \mathrm{KOH}$ in five carbons described by Lota et al. ${ }^{38}$ If one uses $\mathrm{C} / \mathrm{S}_{\mathrm{BET}}$, the capacitance increases from $0.065 \mathrm{~F} \mathrm{~m}^{-2}$ to $0.113 \mathrm{~F} \mathrm{~m}^{-2}$ when the average pore width $\mathrm{L}_{\mathrm{o}}$ decreases from 1.45 to $1.06 \mathrm{~nm}$. This pattern was used to validate the model, as it is similar to the increase reported earlier for $\mathrm{TEABF}_{4} / \mathrm{AN}^{33,35}$ Under these conditions, Eqn. (9) leads to $\varepsilon_{\mathrm{r}}=3.33 \pm 0.57$ (a relatively important uncertainty) and $\mathrm{a}_{\mathrm{o}}=2.56 \pm 0.054 \mathrm{~nm}$. However, as reported recently, ${ }^{10}$ using $\mathrm{S}_{\mathrm{av}}$ instead of $\mathrm{S}_{\mathrm{BET}}$ and correcting for the pseudocapacitance effects shows that $\mathrm{C} / \mathrm{S}_{\mathrm{av}}$ is relatively constant $\left(0.115 \pm 0.004 \mathrm{~F} \mathrm{~m}^{-2}\right)$ and similar to $2 \mathrm{M} \mathrm{H}_{2} \mathrm{SO}_{4}$ shown in Figure 8. Assuming that $\mathrm{a}_{\mathrm{o}}=$ $0.138 \mathrm{~nm},{ }^{48}$ Eqn. (9) now suggests that $\varepsilon_{\mathrm{r}}$ decreases from 7.1 to 4.2 between $1.45 \mathrm{~nm}$ and $1.06 \mathrm{~nm}$. Obviously, $\mathrm{L}_{\mathrm{o}}$ is an average pore width, whereas Eqn. (9) applies to a single pore of width L. This may introduce some uncertainty, but it appears that the use 
of $\mathrm{S}_{\mathrm{av}}$, rather than $\mathrm{S}_{\mathrm{BET}}$, and correcting for pseudocapacitance effects, leads to a new picture.

Since the 'sandwich' model is reasonable in itself, Eqn. (9) remains valid provided that $\varepsilon_{\mathrm{r}}$ decreases with the pore width. This hypothesis can be justified by experimental evidence showing that the relative permittivity of an ionic solution decreases with the solvent to ion ratio. For example, it has been reported that in the case of water filling the micropores of expanding clays ${ }^{49,50}$ such as bentonites, ${ }^{51} \varepsilon_{\mathrm{r}}$ decreases as the interlayer spacing decreases. These slit-shaped micropores consist of negatively charged layers with a constant amount of $\mathrm{Na}^{+}$or $\mathrm{Ca}^{+2}$ ions surrounded by a variable amount of water filling the rest of the micropore volume. The accessible pore width can reach 1 to 1.2 $\mathrm{nm},{ }^{52}$ where the solid contains $40 \%$ of water in weight. This system corresponds formally to the negative electrode of a carbon-based supercapacitor, except that the bentonite layers are not conducting.

At this stage it is interesting to compare our findings with the results of recent advanced modelling of the capacitance in porous carbons. ${ }^{39-42,48,53-55}$ These studies are based on different models, such as Monte Carlo (MC), molecular dynamics (MD), the classical density functional theory (DFT) or modified Poisson-Boltzmann theories (MPB).

First of all, MD simulations suggest that, due to a confinement effect, the dielectric constant of pure water in nanocavities with diameters between 2.44 and $1.22 \mathrm{~nm}$ should be reduced from 71 to $42 .^{53}$ It is a considerable change and one may assume that this effect applies, to some extent, to the dielectric constant of aqueous solutions and of other liquids, for example ionic liquids. Conway ${ }^{56}$ has also pointed out that the dielectric constant of water can vary considerably in the double layer at metallic electrodes and it can be as low as 8 for Au.

The hypothesis of a variable dielectric constant seems also plausible for organic electrolytes with a solvent, as shown in the recent papers of Varghese et al. ${ }^{54}$ and Wang et al. ${ }^{55}$ These studies are based on a modified Poisson-Boltzmann theory and conclude that a field-dependent permittivity significantly reduces the capacitance in cylindrical and spherical pores down to $1 \mathrm{~nm}$. These studies suggest that $\mathrm{C} / \mathrm{S}$ is relatively constant, in particular for $\mathrm{TEABF}_{4} / \mathrm{PC}^{54}$ The hypothesis of a variable $\varepsilon_{\mathrm{r}}$ is therefore a possibility to be further investigated for organic and aqueous electrolytes.

The results obtained by the modelling of $\mathrm{C} / \mathrm{S}$ of ionic liquids are sometimes transposed to the case of $\mathrm{TEABF}_{4} / \mathrm{AN}^{39-41}$ although this electrolyte contains a solvent. This means that the two systems are not necessarily identical, in particular as far as the effect of the 
solvent is concerned. In this context, two recent papers of Jiang et al., ${ }^{40,42}$ based on the classical density functional theory (DFT), are highly relevant. These authors examine first the case of the ionic liquid EMIM-TFSI, ${ }^{40}$ where it is found that $\mathrm{C} / \mathrm{S}$ increases in micropores below $0.9 \mathrm{~nm}$. At higher pore widths, C/S undergoes a series of oscillations around an average value of $0.07 \mathrm{~F} \mathrm{~m}^{-2}$. A similar pattern can be expected if one considers $\mathrm{TEABF}_{4}$ as a pure electrolyte. In the second paper, ${ }^{42}$ the same DFT approach is used, but the solvent is also taken into account. Here, the acetonitrile molecule is considered as a dumb-bell with opposite charges representing its dipole (3.4D). This refined description of the $\mathrm{TEABF}_{4} / \mathrm{AN}$ electrolyte suggests a much smoother pattern for $\mathrm{C} / \mathrm{S}$. It is characterized by an initial oscillation starting with a maximum at $0.5 \mathrm{~nm}(0.12$ $\left.\mathrm{F} \mathrm{m}^{-2}\right)$ and a dip at $0.75 \mathrm{~nm}\left(0.07 \mathrm{~F} \mathrm{~m}^{-2}\right)$. It is followed by a sharp increase and from 0.8 $\mathrm{nm}$ to $3 \mathrm{~nm} \mathrm{C/S}$ varies between 0.08 and $0.10 \mathrm{~F} \mathrm{~m}^{-2}$. In this range, the pattern is similar to that shown in Figure 4 and based on $\mathrm{S}_{\mathrm{av}}$ or $\mathrm{S}_{\text {tot }}\left(\mathrm{CCl}_{4}\right)(\square)$, as opposed to the regular decrease of $\mathrm{C} / \mathrm{S}_{\mathrm{BET}}(\square \mathbf{\Delta})$ between 0.7 and $1.5 \mathrm{~nm}$. (It should also be pointed out that $\mathrm{S}_{\mathrm{av}}$ and $\mathrm{S}_{\text {tot }}\left(\mathrm{CCl}_{4}\right)$ are similar to the geometrical surface area of the slit-shaped micropores used in the modelling, whereas $\mathrm{S}_{\mathrm{BET}}$ differs from these values, as illustrated by Figure 1 . Since aqueous electrolytes such as $2 \mathrm{M} \mathrm{H}_{2} \mathrm{SO}_{4}$ and $6 \mathrm{M} \mathrm{KOH}$ consist of ionic species $\left(\mathrm{H}^{+}, \mathrm{K}^{+}, \mathrm{SO}_{4}^{-2}, \mathrm{OH}^{-}\right)$and a polar solvent, its possible that the model of Jiang et al. proposed for $\mathrm{TEABF}_{4} / \mathrm{AN}$ also applies to these electrolytes. This would correspond to the relatively constant values of $\mathrm{C} / \mathrm{S}_{\mathrm{av}}$ shown in Figure 8 , but it must be confirmed by the same DFT-based modelling applied to these ions.

Taking into account the presence of the solvent visibly modifies the predictions regarding a change in $\mathrm{C} / \mathrm{S}$ with the size of the micropores. The DFT-based modelling does not consider explicitly the relative permittivity and therefore further evidence may be provided by modelling based directly on the hypothesis of a variable $\varepsilon_{\mathrm{r}}$.

\section{Conclusions}

Our study illustrates the importance of a reliable structural characterization of porous carbons used as supercapacitors and, in particular, the determination of the surface area available to the electrolytes. Areas derived from different techniques and taking into account to the size of the ions (e.g. TEA ${ }^{+}$) lead to safer results than the BET method. As a consequence, different conclusions may be drawn as far as the surface-related and the volumetric capacitances are concerned. This should be brought to the attention of theoreticians who rely on experimental data for $\mathrm{C} / \mathrm{S}$, in order to validate their models. 
Studies based on a large number of microporous carbons with pore widths between 0.7 and $1.8 \mathrm{~nm}$ suggest that the surface-related capacitance $\mathrm{C} / \mathrm{S}\left(\mathrm{F} \mathrm{m}^{-2}\right)$ in the $1 \mathrm{M}$ $\mathrm{TEABF}_{4} / \mathrm{AN}$ is practically independent of the micropore width. The same applies to the 1-2 $\mathrm{M} \mathrm{H}_{2} \mathrm{SO}_{4}$ electrolyte after correcting for pseudo-capacitance effects. For untreated carbons, the average value suggested by reliable surface areas such as $\mathrm{S}_{\mathrm{av}}$ or $\mathrm{S}_{\text {tot }}\left(\mathrm{CCl}_{4}\right)$ is around 0.09-0.10 $\mathrm{F} \mathrm{m}^{-2}$. It is also shown that the NLDFT-based PSDs of the carbons would not hide significant changes in the capacitance with the pore width L, thus confirming the reliability of the constant experimental values of $\mathrm{C} / \mathrm{S}$.

Relatively constant values of $\mathrm{C} / \mathrm{S}$, at least in pores of more than $0.8 \mathrm{~nm}$, are also suggested by recent modeling based on DFT and taking into account the solvent. ${ }^{42}$ However, isolated exceptions are not ruled out (for example, variations due to changes in surface conductivity or in chemical composition). On the other hand, the use of $\mathrm{S}_{\mathrm{BET}}$ suggests a decrease in $\mathrm{C} / \mathrm{S}$ between 0.7 and 1.3-1.5 nm (see Figure 4), but this area is unreliable in the case of microporous solids.

The findings based on the surface areas of the carbons are also reflected by the linear plot of the volumetric capacitance $\mathrm{C}_{\mathrm{mi}} / \mathrm{W}_{\mathrm{o}}$ vs. $1 / \mathrm{L}_{\mathrm{o}}$ between 0.7 and $1.6 \mathrm{~nm}$. For locally slit-shaped micropores, the generally accepted model, this correlation also implies a constant value of $\mathrm{C}_{\mathrm{mi}}\left(\mathrm{TEABF}_{4} / \mathrm{AN}\right) / \mathrm{S}$. The higher volumetric capacitance in small micropores may be interesting from a technical point of view, but it can also presents adverse effects due to the fact that the ions' transport during the supercapacitor chargedischarge is more restricted in pores with sizes similar to those of the ions. It also appears that the model of cylindrical pores and its theoretical background, does not apply to typical micropores, as opposed to mesopores.

Constant surface-related capacitances, as suggested experimentally by $\mathrm{C} / \mathrm{S}_{\mathrm{av}}$ or $\mathrm{C} / \mathrm{S}_{\text {tot }}\left(\mathrm{CCl}_{4}\right)$, would be consistent with a decrease of the relative permittivity $\varepsilon_{\mathrm{r}}$ in narrow micropores, as implied by the 'sandwich' model of Feng et al. ${ }^{48}$ and by recent modelling. The hypothesis of a variable $\varepsilon_{\mathrm{r}}$ is also supported by the direct determination of its value in the expanding slit-shaped pores of the water-bentonite system. This system may be regarded as an analogue of the negative electrode in a carbon-based supercapacitor. The consequences of a variable relative permittivity in the micropores will be further investigated. 


\section{Acknowledgements}

Financial support to T.A.C. from EU 7FP (Project Electrograph- 266391) and MICINN (project MAT 2011-25198) is gratefully acknowledged. F.S. wishes to thank the University of Neuchâtel for its constant support beyond his retirement.

\section{References}

1 J. Rouquérol, D. Avnir, C. W. Fairbridge, D. H. Everett, J. M. Haynes, N. Pernicone, J. D. F. Ramsay, K. S. W. Sing and K. K. Unger, Pure Appl. Chem,. 1994, 66, 1739-1758.

2 J. Rouquérol, P. Llewellyn and F. Rouquérol, in Studies in Surface Science and Catalysis, Vol. 160 (Eds.: P.L. Llewellyn, F. Rodríguez-Reinoso, J. Rouquerol, N. Seaton), Elsevier, Amsterdam, 2007, pp. 49-56.

3 K. Sing, Colloid Surf. A, 2001, 187-188, 3-9.

4 T. A. Centeno and F. Stoeckli, Carbon, 2010, 48, 2478-2486.

5 H. Shi, Electrochim. Acta, 1996, 41, 1663-1669.

6 J.C. Palmer, A. Llobet, S.H. Yeon, J.E. Fisher, Y. Shi, Y.Gogotsi and K.E. Gubbins, Carbon, 2010, 48, 1116-1123.

7 O. Barbieri, M. Hahn, A. Herzog and R. Kötz, Carbon, 2005, 43, 1303-1310.

8 Z. Feng, R. Xue and X. Shao, Electrochim. Acta, 2010, 55, 7334-7340.

9 T.A. Centeno and F. Stoeckli, Phys. Chem. Chem. Phys., 2011, 13, $12403-$ 12406.

10 T. A. Centeno and F. Stoeckli, Electrochim. Acta, 2011, 56, 7334-7339.

11 T.A. Centeno and F. Stoeckli, Electrochem. Comm., 2012, 16, 34-36.

12 F. Stoeckli and T.A. Centeno, Phys. Chem. Chem. Phys., 2012, 14, 1158911591.

13 F. Stoeckli and T. A. Centeno, Carbon, 1997, 35, 1097-1100.

14 J. Fryer, Carbon 1981, 19, 431-439.

15 A. Oberlin, A. Villey and A. Combaz, Carbon, 1980, 18, 347-353.

16 A. Oberlin, A. Villey and A. Combaz, J. Microsc. Spectrosc. Electron., 1982, 7, 327.

17 F. Stoeckli, Carbon, 1990, 28, 1-6.

18 M.M. Dubinin, Carbon, 1989 27, 457-467.

19 F. Stoeckli, in Porosity in carbons:Characterization and Applications (Ed: .J. Patrick), Arnold, London 1995, pp. 67-92. 
20 F. Stoeckli, Russ. Chem. Bull. Int. Ed., 2001, 50, 2265-2270.

21 N. Setoyama, T. Suzuki and K. Kaneko, Carbon, 1998, 36, 1459-1467.

22 E. Fernández, D. Hugi-Cleary, V. López-Ramón and F. Stoeckli, Langmuir , 2003, 19, 9719-9723.

23 F. Stoeckli and D. Hugi-Cleary, Russ. Chem. Bull. Int. Ed., 2001, 50, 20602063.

24 P.I. Ravikovitch, A. Vishniakov, R.A. Russo and V. Neimark, Langmuir, 2000, 16, 2311-2320.

25 F. Stoeckli, A. Guillot, D. Hugi-Cleary and A. M. Slasli, Carbon, 2000, 38, 938941.

26 F. Stoeckli, A. Guillot, A. M. Slasli and D. Hugi-Cleary, Carbon, 2002, 40, 211 215.

27 F. Stoeckli, A. Guillot, A. M. Slasli and D. Hugi-Cleary, Carbon, 2002, 40, 383388.

28 F. Stoeckli, M.V. López-Ramón, D. Hugi-Cleary and A. Guillot, Carbon, 2001, 39, 1115-1116.

29 S.J. Gregg and K.S.W. Sing, Adsorption, Surface Area and Porosity, Academic Press, New York, 1982.

30 F. Rouquérol, L. Luciani, Ph. Llewellyn, R. Denoyel and J. Rouquérol, in 'Editions Techniques de l’Ingénieur, Paris, 2004, 1-24.

31 Iso-15901 'Pore size distribution and porosity of solid materials by mercury porosimetry and gas adsorption' Part 3: Analysis of micropores by gas adsorption.

32 A.V. Neimark, Y. Lin, P.I. Ravikovitch and M. Thommes, Carbon, 2009, 47, 1617-1628.

33 J. Chmiola, G. Yushin, Y. Gogotsi, C. Portet, P. Simon, and P.L.Taberna, Science, 2006, 313, 1760-1763.

34 T.A. Centeno, J.A. Fernández and F. Stoeckli, Carbon, 2008, 46, 1025-1030

35 P. Simon and Y. Gogotsi, Nat. Mater., 2008, 7, 845-854.

36 J.A. Fernández, M. Arulepp, J. Leis, F. Stoeckli and T.A. Centeno, Electrochim. Acta, 2008, 53, 7111-7116.

37 T.A. Centeno, M. Hahn, J.A. Fernández, R. Kötz and F. Stoeckli, Electrochem. Commun., 2007, 9, 1242-1246. 
38 G. Lota, T.A. Centeno, E. Frackowiak and F. Stoeckli, Electrochim. Acta, 2008, 53, 2210-2216.

39 G. Feng and P.T. Cummings, J. Phys. Chem. Lett.., 2011, 2, 2859-2864.

40 D. Jiang, Zh. Jin and J. Wu, Nano Lett., 2011, 11, 5373-5377.

41 S. Kondrat, C.S. Pérez, V. Presser, Y. Gogotsi and A.A. Kornyshev, Energy Environ. Sci., 2012, 5, 6474-6479.

42 D. Jiang, Zh. Jin, D. Henderson and J. Wu, Phys.Chem. Lett., 2012, 3, $1727-$ 1731.

43 M.J. Bleda-Martínez, J.A. Maciá-Agulló, D. Lozano-Castelló, E. Morallón, D. Cazorla-Amorós and A. Linares-Solano, Carbon, 2005, 43, 2677-2684.

44 T. A. Centeno and F. Stoeckli, Electrochim. Acta, 2006, 52, 560-566.

45 V. Barranco, M. A. Lillo-Rodenas, A. Linares-Solano, A. Oya, F. Picó, J. Ibañez, F. Agullo-Rueda, J. M. Amarilla and J. M. Rojo, J. Phys. Chem. C, 2010, 114, 10302-10307.

46 J. Huang, B.G. Sumpter and V. Meunier, Angew. Chem. Int. Ed., 2008, 47, 520524.

47 J. Huang, B.G. Sumpter and V. Meunier, Chem. Eur. J., 2008, 14, 6614-6626.

48 G. Feng, R. Qiao, J. Huang, B. G. Sumpter and V. Meunier, ACS Nano, 2010, 4, 2382-2390.

49 P. Cosenza and A. Tabbagh, Appl. Clay Sci., 2004, 26, 21-36.

50 V. Saltas, F. Vallianatos and D. Triantis, J. Non-Cryst. Solids, 2008, 354, $5533-$ 5541.

51 H. Bidadi, P.A. Schroederer;and T. Pinnavaia, J. Phys. Chem. Solids, 1988, 49, 1435-1440.

52 F. Kraehenbuehl, F. Stoeckli, F. Brunner, G. Kahr and A. Müller-Vonmoos, Clay Minerals, 1987, 22, 1-9.

53 A. Senapati and A. Chandral, J. Phys. Chem. B, 2001, 105, 5106-5109.

54 J. Varghese, H. Wang and L. Pilon, J. Electrochem. Soc., 2011, 158, A1106A1114.

55 H. Wang and L. Pilon, J. Phys. Chem. C , 2011, 115, 16711-16719.

56 B. E. Conway Electrochemical Supercapacitors, Kluwer Academic/Plenum Publishers, New York 1999, 153. 